\title{
ПРЕДВАРИТЕЛЬНЫЙ ДОГОВОР: ЗАЩИТА ПРАВ УЧАСТНИКОВ ДОЛЕВОГО СТРОИТЕЛЬСТВА
}

\begin{abstract}
Аннотация: Предмет исследования составляют нормы гражданского законодательства, регулирующие общественные отношения в сфере защиты прав граждан при участии в долевом строительстве многоквартирных домов или иных объектов недвижимости, а также теоретические воззрения в указанной области, судебная практика. Исследуются проблемы привлечения застройщиком денежных средств участников долевого строительства по предварительному договору. В частности, правомерность включения в предварительный договор условий о задатке, об оплате неустойки за неисполнение обязательства по заключению основного договора. В качестве методологической основы исследования используется общенаучный диалектический метод познания. При проведении исследования также применяются аналитический, логический, формально-юридический и инье методы научного познания. Научная новизна состоит в том, что автор не только анализирует проблемы, связанные с защитой прав участников долевого строительства, заключивщих предварительный договор, но и предлагает пути их решения. Данные предложения будут способствовать повышению гарантий зашиты прав и имущественных интересов участников долевого строительства.

Abstract: This research examines the norms of civil legislation that regulate the social relations in the area of protection of the rights of citizens in the cases of shared-equity construction of multi-unit condominiums or other types of real estate. It also includes the theoretical views within this subject and looks at court rulings. A research is conducted on the problems associated with builders raising the capital for construction from the shared-equity participants on the preliminary contract basis. This includes the legality of earnest payment clause in the preliminary agreement and penalties for breach of agreement to execute the final contract. The scientific novelty consists in the fact that the author not only analyzes the problems related to the protection of rights of the parties involved in the shared-equity construction that have entered into a preliminary contract, but also proposes their solutions. These proposals would contribute to the increase of ensuring protection of rights and property interests of the parties of the shared-equity construction projects. Ключевые слова: Предварительный договор, защита прав, потребитель, задаток, долевое строительство, неустойка, застройщик, возмещение убытков, недвижимость, денежные средства граждан.
\end{abstract}

Keywords: Preliminary contract, protection of rights, consumer, earnest payment, shared-equity construction, breach of contract, restitution, real estate.

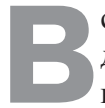

се большее распространение в современном гражданском обороте получают предварительные договоры. Использование юридической конструкции предварительного договора имеет своей целью юридически связать стороны еще до того, как они подпишут окончательный договор.

В юридической литературе исследованию вопроса заключения предварительного договора уделяется достаточно много внимания ${ }^{1}$. Как справедливо указывает О.Г. Ершов: «В связи с этим становится очевидным, что применение конструкции предварительного договора в строительстве дает основным участникам строительного рынка преимущества, главное из которых - возможность установления предварительных хозяйственных связей, в которых взаимно учтены интересы сторон» ${ }^{2}$.

Федеральный закон N 214-Ф3 от 30 декабря 2004 г. «Об участии в долевом строительстве многоквартирных домов и иных объектов недвижимости и о внесении изменений в

\footnotetext{
${ }^{1}$ См.: Дегтярева А., Смородинов М., Андрианов Н., Денисов А., Чистякова Ю. За заключение предварительных договоров с нарушением Закона от 30.12.2004 N 214-Ф3 об участии в долевом строительстве могут оштрафовать по-крупному // Жилищное право. 2014. N 7. С. 99 - 112; Колоколов Н. Долевой прием // ЭЖ-Юрист. 2014. N 8. C. 14

${ }^{2}$ Ершов О. Г. Предварительный договор в строительстве // Право и экономика. 2010. N 11. С. 39.
}

некоторые законодательные акты Российской Федерации» (далее-Закон об участии в долевом строительстве) не содержит запрета на применение конструкции предварительного договора в долевом строительстве.

В соответствии со ст. 429 Гражданского кодекса Российской Федерации ${ }^{4}$ (далее - ГК РФ) по предварительному договору стороны обязуются заключить в будущем договор о передаче имущества, выполнении работ или оказании услуг (основной договор) на условиях, предусмотренных предварительным договором.

Таким образом, сутью обязательства, порождаемого предварительным договором, являются взаимные обязанности сторон по заключению в будущем основного договора на условиях, которые предусмотрены предварительным договором. Предварительный договор должен содержать условия, позволяющие установить предмет, а также другие существенные условия основного договора ${ }^{5}$.

\footnotetext{
${ }^{3}$ Федеральный закон N 214-Ф3 от 30 декабря 2004 г. «Об участии в долевом строительстве многоквартирных домов и иных объектов недвижимости и о внесении изменений в некоторые законодательные акты Российской Федерации» // Собрание законодательства Российской Федерации. 2005. N 1 (часть 1). Ст. 40.

${ }^{4}$ Гражданский кодекс Российской Федерации (часть первая) // Собрание законодательства Российской Федерации. 1994. N 32. Ст. 3301.

${ }_{5}^{5}$ Крутикова С.В. Применение конструкции предварительного договора в долевом строительстве // Проблемы защиты прав человека
} 
DOI: $10.7256 / 1811-9018.2014 .12 .13656$

При цитировании этой статьи сноска на doi обязательна

\section{Право и политика $12(180) \cdot 2014$}

Следовательно, заключение предварительного договора является своего рода гарантом исполнения обязательств каждой из сторон в будущем.

Вместе с тем в научной литературе встречается негативное отношение к возможности заключения предварительного договора с участником долевого строительства ${ }^{6}$. И это понятно, если учесть возросшее количество споров, вытекающих из заключения предварительного договора.

К отношениям, вытекающим из договора, заключенного гражданином - участником долевого строительства исключительно для личных, семейных, домашних и иных нужд, не связанных с осуществлением предпринимательской деятельности, применяется Закон РФ от 7 февраля 1992 г. N 2300-1 «О защите прав потребителей» (далее - Закон о защите прав потребителей) в части, не урегулированной Законом об участии в долевом строительстве. Возникает вопрос: возможно ли применение к отношениям сторон предварительного договора Закона о защите прав потребителей?

По данному вопросу было дано разъяснение Пленума Верховного Суда РФ в Постановлении от 28.06.2012 N 17 «О рассмотрении судами гражданских дел по спорам о защите прав потребителей» ${ }^{8}$ (далее - Постановление Пленума ВС РФ от 28.06.2012 N 17). Согласно п. 4 Постановления Пленума ВС РФ от 28.06.2012 N 17 к отношениям сторон предварительного договора (статья 429 ГК РФ), по условиям которого гражданин фактически выражает намерение на возмездной основе заказать или приобрести в будущем товары (работы, услуги) исключительно для личных, семейных, домашних, бытовых и иных нужд, не связанных с осуществлением предпринимательской деятельности, применяется законодательство о защите прав потребителей.

Следовательно, на отношения по предварительному договору с участником долевого строительства распространяются общие положения Закона о защите прав потребителей, касающиеся предоставления необходимой информации, возмещения морального вреда и т.д.

При осуществлении защиты прав потребителей в сфере долевого участия в строительстве необходимо также принимать во внимание, что данные отношения во многом регламентируются нормами административного права. Так, застройщик не вправе привлекать денежные средства участника долевого строительства до государственной регистрации договора участия в долевом строительстве. В случае нарушения этого правила, застройщик может быть привлечен к административной ответственности в соответствии с ч. 1 ст. 14.28 Кодекса Российской Федерации об административных правонарушениях ${ }^{9}$.

в Российском судопроизводстве: Материалы Всероссийской научнопрактической конференции, г. Тюмень, 6-7 февраля 2009 г.: В 2 ч. Ч.2. Тюмень: Издательство ТюмГУ, 2009. С. 103.

${ }^{6}$ Гагаева К., Тычкин $K$. Мошеннические схемы: от «обналички» маткапитала до рейдерства // Жилищное право. 2012. N 9. С. 87.

7 Закон РФ от 7 февраля 1992 г. N 2300-1 «О защите прав потребителей» // Собрание законодательства Российской Федерации. 1996. N 3. Ст. 140.

8 Постановление Пленума Верховного Суда РФ от 28.06.2012 N 17 «О рассмотрении судами гражданских дел по спорам о защите прав потребителей» // Бюллетень Верховного Суда РФ. 2012. № 9.

${ }^{9}$ Кодекс Российской Федерации об административных правонарушениях Собрание законодательства Российской Федерации. 2002. № 1 (ч.1). Ст. 1 .
Применяя к нарушителям прав потребителей в сфере долевого участия в строительстве меры административного воздействия, следует учитывать положения об осуществлении государственного контроля (надзора) в области долевого строительства объектов недвижимости, одним из направлений которого является контроль за целевым использованием застройщиком денежных средств, уплачиваемых участниками долевого строительства по договору, для строительства (создания) многоквартирных домов и (или) иных объектов недвижимости в соответствии с Законом об участии в долевом строительстве.

Государственный контроль (надзор) в области долевого строительства многоквартирных домов и (или) иных объектов недвижимости осуществляется в соответствии с Законом об участии в долевом строительстве уполномоченным органом исполнительной власти субъекта Российской Федерации, на территории которого осуществляется данное строительство.

Контроль и надзор в области долевого строительства многоквартирных домов и (или) иных объектов недвижимости на территории Тюменской области осуществляются уполномоченным органом исполнительной власти Тюменской области, которым является главное управление строительства Тюменской области ${ }^{10}$.

Проведение надзорных и контрольных мероприятий имеет большое значение для осуществления градостроительной деятельности строительными организациями в рамках действующего законодательства. В ходе данных мероприятий принимаются решения, направленные на обеспечение деятельности указанных субъектов в соответствии с законодательно установленными требованиями и правилами, защиту прав и законных интересов участников долевого строительства.

Однако, как свидетельствует судебная практика, несмотря на совершенствование законодательства об участии в долевом строительстве, по-прежнему при привлечении денежных средств граждан допускаются многочисленные нарушения со стороны застройщиков.

Согласно информации, содержащейся в «Обзоре практики разрешения судами споров, возникающих в связи с участием граждан в долевом строительстве многоквартирных домов и иных объектов недвижимости» (утв. Президиумом Верховного Суда РФ 04.12.2013 ${ }^{11}$ ), основу претензий граждан, в случаях когда заключен предварительный договор, как правило, составляют:

- нарушение порядка привлечения денежных средств участников долевого строительства, путем включения в предварительный договор условия о передаче денежных средств застройщику в качестве оплаты объекта долевого строительства;

\footnotetext{
${ }^{10}$ Постановление Правительства Тюменской области от 1 июня 2009 г. N 146-п «Об утверждении Положения о главном управлении строительства Тюменской области» [Электронный ресурс]. Документ опубликован не был. Доступ из справочно-правовой системы «КонсультантПлюс» (дата обращения 12.11.2014).

${ }^{11}$ Обзор практики разрешения судами споров, возникающих в связи с участием граждан в долевом строительстве многоквартирных домов и иных объектов недвижимости (утв. Президиумом Верховного Суда РФ 04.12.2013) // Бюллетень Верховного Суда РФ. 2014. № 3.
} 
- неисполнение условий предварительного договора: отказ или уклонение контрагента от заключения основного договора.

Итак, первая категория нарушений наблюдается еще на стадии заключения договора с участником долевого строительства, когда в предварительный договор включено условие о передаче денежных средств застройщику в качестве оплаты объекта долевого строительства.

Следует отметить, что основной причиной применения конструкции предварительного договора является потребность застройщиков в денежных средствах для создания объектов долевого строительства.

В связи с этим, включение застройщиком в предварительный договор условий о привлечении денежных средств на практике порождает ряд вопросов, основные из которых мы обозначим.

Согласно п. 8 Постановления Пленума ВАС РФ от 11.07.2011 N 54 «О некоторых вопросах разрешения споров, возникающих из договоров по поводу недвижимости, которая будет создана или приобретена в будущем» ${ }^{12}$ (далее - Постановление Пленума ВАС РФ от 11.07.2011 N 54). Если сторонами заключен договор, поименованный ими как предварительный, в соответствии с которым они обязуются заключить в будущем на предусмотренных им условиях основной договор о продаже недвижимого имущества, которое будет создано или приобретено в последующем, но при этом предварительный договор устанавливает обязанность приобретателя имущества до заключения основного договора уплатить цену недвижимого имущества или существенную ее часть, то суды должны квалифицировать его как договор купли-продажи будущей недвижимой вещи с условием о предварительной оплате. Споры, вытекающие из указанного договора, подлежат разрешению в соответствии с правилами ГК РФ о договоре купли-продажи. ${ }^{13}$

Таким образом, арбитражные суды классифицируют предварительные договоры с условием об оплате цены объекта долевого строительства как договоры купли-продажи будущей недвижимой вещи. Мы видим, что включение в предварительный договор условия об оплате стоимости недвижимости, трансформирует предварительный договор в договор купли-продажи. Соответственно, при купле-продаже возникает обязательство по передаче имущества (пусть даже в будущем), а не обязательство заключения основного договора в будущем.

Если обратиться к Закону о долевом строительстве, то застройщик вправе привлекать денежные средства участников долевого строительства только после получения в установленном порядке разрешения на строительство, опубликования, размещения и (или) представления проектной декларации и государственной регистрации права собственности на земельный участок, предоставленный для строительства (создания) многоквартирного дома, или договора аренды, субаренды такого земельного участка (ч. 1 ст. 3 Закона).

\footnotetext{
12 Постановление Пленума ВАС РФ от 11.07.2011 N 54 «О некоторых вопросах разрешения споров, возникающих из договоров по поводу недвижимости, которая будет создана или приобретена в будущем» // Вестник ВАС РФ. 2011. N 9.

${ }^{13}$ Бычков A. Защита от недобросовестного застройщика // ЭЖ-Юрист. 2013. N 48. C. 15.
}

В Постановлении Президиума ВАС РФ от 23.03.2010 N 13863/09 по делу N A47-3050/200914 подчеркнуто, что обязательным условием для застройщика также является наличие договора, заключенного в письменной форме и прошедшего государственную регистрацию.

Именно выполнение всех вышеперечисленных требований и предоставляет застройщику право привлекать денежные средства граждан.

Следовательно, по смыслу Закона о долевом строительстве заключение предварительного договора возможно, но привлечение по нему денежных средств граждан для строительства - незаконно.

Следует учитывать, что предварительный договор и обязательство, порождаемое им о заключении в будущем основного договора, безвозмездны. Так, исполнение обязанностей сторон по заключению основного договора не обусловлено каким-либо встречным предоставлением или платой со стороны контрагента.

Как справедливо отмечает А.С. Троенко: «Безвозмездность эта вытекает из сущности предварительного договора, императивно установлена законом и не может быть изменена даже исходя из принципа свободы договора, так как любая свобода имеет свои пределы, ограниченные законом» ${ }^{15}$.

В рамках предварительного договора не может осуществляться полное или частичное исполнение сторонами своих обязательств по еще не заключенному основному договору.

Ключевое разъяснение по поводу привлечения средств граждан дал Пленум ВАС РФ в Постановлении от 11.07.2011 N 54. По мнению высших арбитров, нормы Закона об участии в долевом строительстве являются специальными по отношению к правилам ГК РФ о купле-продаже будущей вещи. Поэтому привлекать средства граждан для строительства многоквартирных домов и (или) иных объектов недвижимости возможно только способами, указанными в ч. 2 ст. 1 Закона о долевом строительстве.

Вместе с тем в своем стремлении привлечь денежные средства участников на начальном этапе строительства застройщики при заключении предварительного договора оформляют их как задаток.

Задатком признается денежная сумма, выдаваемая одной из договаривающихся сторон в счет причитающихся с нее по договору платежей другой стороне, в доказательство заключения договора и в обеспечение его исполнения (ст. 380 ГК РФ).

Таким образом, из буквального толкования статьи следует, что задаток вносится в счет причитающихся платежей по заключаемому сторонами договору, т.е. задатком может быть обеспечено только исполнение денежного обязательства.

При выборе конструкции задатка в предварительном договоре нередко указывается, что в случае неисполнения застройщиком обязанности по заключению основного договора он возвращает плательщику двойную сумму задатка, а в случае неисполнения плательщиком задатка той же обязанности сумма задатка остается у застройщика.

\footnotetext{
${ }^{14}$ Постановление Президиума ВАС РФ от 23.03.2010 N 13863/09 по делу N А47-3050/2009 // Вестник ВАС РФ. 2010. N 7.

${ }^{15}$ Троенко А.С. Применение соглашения о задатке в конструкции предварительного договора купли-продажи недвижимости // Бюллетень нотариальной практики. 2008. № 3. С. 18.
} 
DOI: $10.7256 / 1811-9018.2014 .12 .13656$

При цитировании этой статьи сноска на doi обязательна

\section{Право и политика $12(180) \cdot 2014$}

Казалось бы, данная конструкция укладывается в рамки ст. 381 ГК РФ, при этом, однако, игнорируется следующее. Согласно п. 1 ст. 380 ГК РФ, обязательным признаком задатка является уплата его в счет платежей, причитающихся застройщику от плательщика. Таким образом, задаток всегда уплачивается в счет покупной цены.

Вместе с тем в научной литературе встречаются суждения о том: «что по предварительным договорам оплата не осуществляется, может быть внесен лишь обеспечительный договорной платеж, который не может составлять 100 процентов от цены основного договора $\rangle^{16}$. По мнению Н.К. Евстратовой: «Поскольку оплата в полном размере цены договора фактически не будет нести обеспечительную функцию и стимулировать продавца к заключению основного договора, это будет свидетельствовать о том, что основной целью подписания предварительного договора с обеспечением в размере 100 процентов от цены основного договора является получение продавцом денежных средств в размере полной стоимости недвижимости» ${ }^{17}$.

Однако возможность уплаты даже части покупной цены по предварительному договору, называемой обеспечительным платежом, представляется крайне сомнительной по причинам, изложенным выше.

Ранее в судебной практике не существовало единообразного подхода к решению вопроса о возможности применения задатка в конструкции предварительного договора.

В настоящее время в своих решениях многие арбитражные суды ссылаются на постановление Президиума ВАС РФ от 19 января 2010 г. N 13331/09 ${ }^{18}$. Согласно правовой позиции, изложенной в данном постановлении, применение задатка в качестве способа обеспечения исполнения обязательств по предварительному договору невозможно, поскольку в силу закона обязательства предварительного договора носят неденежный характер.

В то же время Проект Федерального закона N 47538-6 «О внесении изменений в части первую, вторую, третью и четвертую Гражданского кодекса Российской Федерации, а также в отдельные законодательные акты Российской Федерации» ${ }^{19}$ в статье 380 содержит положение, допускающее обеспечение задатком предварительного договора.

Представляется, что принятие ст. 380 ГК РФ в новой редакции решило бы проблему обеспечения задатком предварительного договора (если предусмотренный в нем основной договор порождает денежное обязательство), и участники гражданских отношений смогли бы использовать

\footnotetext{
${ }^{16}$ Евстратова Н.К. Практика применения договора долевого участия в строительстве и предварительного договора // Имущественные отношения в Российской Федерации. 2014. N 7. С. 94.

17 Там же. С. 94.

18 Постановление Президиума ВАС РФ от 19.01.2010 N 13331/09 по делу N A40-59414/08-7-583 [Электронный ресурс]. Документ опубликован не был. Доступ из справочно-правовой системы «КонсультантПлюс» (дата обращения 12.11.2014).

19 Проект Федерального закона N 47538-6 «О внесении изменений в части первую, вторую, третью и четвертую Гражданского кодекса Российской Федерации, а также в отдельные законодательные акты Российской Федерации» [Электронный ресурс]. Документ опубликован не был. Доступ из справочно-правовой системы «КонсультантПлюс» (дата обращения 12.11.2014).
}

данный способ обеспечения применительно к предварительному договору.

Еще одним видом нарушений, встречающихся при заключении предварительных договоров с участником долевого строительства является неисполнение обязательства по заключению основного договора.

Широкое применение предварительного договора обусловлено тем, что предварительный договор дает гарантии установления будущих хозяйственных связей, поскольку обеспечивается принудительной силой исполнения. В частности, если сторона, заключившая предварительный договор, уклоняется от заключения основного договора, возможно применение п. 4 ст. 445 ГК РФ, допускающего обращение заинтересованной стороны в суд с требованием о понуждении заключения основного договора.

Что касается неустойки, то применение штрафных санкций за отказ или уклонение контрагента от заключения основного договора не регламентировано нашим законодательством. Единственное последствие подобного отказа, о котором идет речь в ст. 429 ГК РФ, - это возможность обращения в суд с требованием о возмещении убытков, вызванных уклонением или отказом от заключения основного договора. Сторона, необоснованно уклоняющаяся от заключения договора, должна возместить другой стороне причиненные этим убытки.

На практике имеются различные подходы при разрешении вопроса о правомерности включения в предварительный договор условия о неустойке за неисполнение обязательства по заключению основного договора.

Согласно первой позиции данное условие предварительного договора ничтожно как противоречащее закону, поскольку положения ст. 429, 450 ГК РФ не предусматривают ответственности за расторжение договора в виде штрафа. В п. 5 ст. 429 ГК РФ названы только два последствия необоснованного уклонения стороны от заключения договора: другая сторона вправе понудить ее заключить договор и взыскать убытки, причиненные уклонением от заключения договора ${ }^{20}$.

В соответствии со второй позицией п. 5 ст. 429 ГК РФ не исключает возможности применения неустойки к нарушителю предварительного договора. Если учесть, что предварительный договор является в определенном смысле самостоятельным гражданско-правовым обязательством, и, следовательно, неисполнение или ненадлежащее исполнение его условий может повлечь взыскание неустойки (ст. 330 ГК РФ). По мнению О.А. Беляевой, именно такой подход к установлению условия о неустойке является весьма оправданным и целесообразным ${ }^{21}$.

Президиум Высшего Арбитражного Суда Российской Федерации, в целях обеспечения единообразного подхода в толковании и применении арбитражными судами положений статей $330,429,445$ ГК РФ, принял постановление от 12.02.2013 N 13585/12 по делу N А43-25969/2011²2.

\footnotetext{
${ }^{20}$ Постановление ФАС Волго-Вятского округа от 11.11 .2010 по делу N A79-13435/2009 [Электронный ресурс]. Документ опубликован не был. Доступ из справочно-правовой системы «КонсультантПлюс» (дата обращения 12.11.2014).

${ }^{21}$ Беляева О.А. Предпринимательское право: Учебное пособие / под ред. В.Б. Ляндреса. М.: КОНТРАКТ, ИНФРА. М, 2009. С. 218.

${ }^{22}$ Постановление Президиума ВАС РФ от 12.02.2013 N 13585/12 по делу N А43-25969/2011 // Вестник ВАС РФ. 2013. N 6.
} 
DOI: $10.7256 / 1811-9018.2014 .12 .13656$

При цитировании этой статьи сноска на dоі обязательна

Юридический практикум

В нем Президиум ВАС РФ отметил, что положения п. п. 1, 5 ст. 429 ГК РФ в совокупности с положениями п. 4 ст. 445 ГК РФ устанавливают только гражданско-правовые последствия уклонения стороны предварительного договора от заключения основного договора и не регулируют отношений, связанных с обеспечением исполнения обязательств, к которым относится неустойка.

Вместе с этим Президиум ВАС РФ указал, что поскольку гражданское законодательство не содержит норм, которые запрещают применение сторонами неустойки, в целях обеспечения исполнения обязательств, предусмотренных предварительным договором, то в силу ст. 394 ГК РФ условие об уплате неустойки за неисполнение обязательства по заключению основного договора может быть включено в предварительный договор.

Проведенное исследование применения конструкции предварительного договора в долевом строительстве позволяет сделать следующие выводы:
Законодательство об участии в долевом строительстве не устанавливает каких-либо особых мер защиты прав и законных интересов участников долевого строительства при заключении предварительного договора. К отношениям сторон предварительного договора применяется Закон о защите прав потребителей.

Застройщик, осуществляющий деятельность по строительству объектов долевого строительства, не вправе привлекать денежные средства участников долевого строительства на основании предварительного договора.

Стороны не вправе включать в предварительный договор условие о задатке.

Условие об уплате неустойки за неисполнение обязательства по заключению основного договора (договора об участии в долевом строительстве) может быть включено в предварительный договор.

\section{Библиография:}

1. Беляева О.А. Предпринимательское право: Учебное пособие / под ред. В.Б. Ляндреса. М.: КОНТРАКТ, ИНФРА-М, 2009. 352 с.

2. Бычков А. Защита от недобросовестного застройщика // ЭЖ-Юрист. 2013. N 48. С. 15.

3. Гагаева К., Тычкин К. Мошеннические схемы: от «обналички» маткапитала до рейдерства // Жилищное право. 2012. N 9. С. 87-96.

4. Дегтярева А., Смородинов М., Андрианов Н., Денисов А., Чистякова Ю. За заключение предварительных договоров с нарушением Закона от 30.12.2004 N 214-ФЗ об участии в долевом строительстве могут оштрафовать по-крупному // Жилищное право. 2014. N 7. С. 99-112.

5. Евстратова Н.К. Практика применения договора долевого участия в строительстве и предварительного договора // Имущественные отношения в Российской Федерации. 2014. N 7. С. 93-101.

6. Ершов О. Г. Предварительный договор в строительстве // Право и экономика. 2010. N 11. С. 38-44.

7. Крутикова С.В. Применение конструкции предварительного договора в долевом строительстве // Проблемы защиты прав человека в Российском судопроизводстве: Материалы Всероссийской научно-практической конференции, г. Тюмень, 6-7 февраля 2009 г.: В 2 ч. Ч.2. Тюмень: Издательство ТюмГУ, 2009. С. 103-107.

8. Колоколов Н. Долевой прием // ЭЖ-Юрист. 2014. N 8. С. 14.

9. Троенко А.С. Применение соглашения о задатке в конструкции предварительного договора купли-продажи недвижимости // Бюллетень нотариальной практики. 2008. № 3. С.18-21.

10. Богдан В.В. Актуальные проблемы договорного регулирования правоотношений с участием потребителей // NB: Вопросы права и политики. - 2014. - 11. - C. 26 - 35. DOI: 10.7256/2305-9699.2014.11.13354. URL: http://www.e-notabene.ru/lr/article_13354.html

\section{References (transliterated):}

1. Belyaeva O.A. Predprinimatel'skoe pravo: Uchebnoe posobie / pod red. V.B. Lyandresa. M.: KONTRAKT, INFRA-M, 2009.352 s.

2. Bychkov A. Zashchita ot nedobrosovestnogo zastroishchika // EZh-Yurist. 2013. N 48. S. 15.

3. Gagaeva K., Tychkin K. Moshennicheskie skhemy: ot "obnalichki” matkapitala do reiderstva // Zhilishchnoe pravo. 2012. N 9. S. 87-96.

4. Degtyareva A., Smorodinov M., Andrianov N., Denisov A., Chistyakova Yu. Za zaklyuchenie predvaritel'nykh dogovorov s narusheniem Zakona ot 30.12.2004 N 214-FZ ob uchastii v dolevom stroitel'stve mogut oshtrafovat' po-krupnomu // Zhilishchnoe pravo. 2014. N 7. S. 99-112.

5. Evstratova N.K. Praktika primeneniya dogovora dolevogo uchastiya v stroitel'stve i predvaritel'nogo dogovora // Imushchestvennye otnosheniya v Rossiiskoi Federatsii. 2014. N 7. S. 93-101.

6. Ershov O. G. Predvaritel'nyi dogovor v stroitel'stve // Pravo i ekonomika. 2010. N 11. S. 38-44

7. Krutikova S.V. Primenenie konstruktsii predvaritel'nogo dogovora v dolevom stroitel'stve // Problemy zashchity prav cheloveka v Rossiiskom sudoproizvodstve: Materialy Vserossiiskoi nauchno-prakticheskoi konferentsii, g. Tyumen', 6-7 fevralya 2009 g.: V 2 ch. Ch.2. Tyumen': Izdatel'stvo TyumGU, 2009. S. 103-107.

8. Kolokolov N. Dolevoi priem // EZh-Yurist. 2014. N 8. S. 14.

9. Troenko A.S. Primenenie soglasheniya o zadatke v konstruktsii predvaritel'nogo dogovora kupli-prodazhi nedvizhimosti // Byulleten' notarial'noi praktiki. 2008. № 3. S.18-21.

10. Bogdan V.V. Aktual'nye problemy dogovornogo regulirovaniya pravootnoshenii s uchastiem potrebitelei // NB: Voprosy prava i politiki. - 2014. - 11. - C. 26 - 35. DOI: 10.7256/2305-9699.2014.11.13354. URL: http://www.e-notabene.ru/lr/article_13354.html 